\title{
PERICYTE PLASTICITY - COMPARATIVE INVESTIGATION OF THE ANGIOGENIC AND MULTILINEAGE POTENTIAL OF PERICYTES FROM DIFFERENT HUMAN TISSUES
}

\author{
M. Herrmann ${ }^{1}$, J.J. Bara ${ }^{1}$, C.M. Sprecher ${ }^{1}$, U. Menzel $^{1}$, J.M. Jalowiec ${ }^{1}$, R. Osinga ${ }^{2,3}$, A. Scherberich ${ }^{3}$, M. Alini $^{1}$ \\ and S. Verrier ${ }^{1, *}$ \\ ${ }^{1}$ AO Research Institute Davos, Davos, Switzerland \\ ${ }^{2}$ Department of Plastic, Reconstructive, Aesthetic and Hand Surgery, Basel University Hospital, Basel, Switzerland \\ ${ }^{3}$ Department of Biomedicine, Basel University Hospital, Basel, Switzerland
}

\begin{abstract}
Pericyte recruitment is essential for the stability of newly formed vessels. It was also suggested that pericytes represent common ancestor cells giving rise to mesenchymal stem cells (MSCs) in the adult. Here, we systematically investigated pericytes and MSCs from different human tissues in terms of their angiogenic and multilineage differentiation potential in vitro in order to assess the suitability of the different cell types for the regeneration of vascularised tissues. Magnetic-activated cell sorting $\left(\mathrm{MACS}^{\circledR}\right)$ was used to enrich CD34-CD146+ pericytes from adipose tissue (AT) and bone marrow (BM). The multilineage potential of pericytes was assessed by testing their capability to differentiate towards osteogenic, adipogenic and chondrogenic lineage in vitro. Pericytes and endothelial cells were co-seeded on Matrigel ${ }^{\mathrm{TM}}$ and the formation of tube-like structures was examined to study the angiogenic potential of pericytes. MSCs from AT and BM were used as controls. CD34-CD146+ cells were successfully enriched from AT and BM. Only BM-derived cells exhibited trilineage differentiation potential. ATderived cells displayed poor chondrogenic differentiation upon stimulation with transforming growth factor- $\beta 1$. Interestingly, osteogenic differentiation was more efficient in AT-PC and BM-PC compared to the respective full MSC population. Matrigel ${ }^{\mathrm{TM}}$ assays revealed that pericytes from all tissues integrated into tube-like structures. We show that $\mathrm{MACS}^{\circledR}$-enriched pericytes from BM and AT have the potential to regenerate tissues of different mesenchymal lineages and support neovascularisation. MACS ${ }^{\circledR}$ represents a simple enrichment strategy of cells, which is of particular interest for clinical application. Finally, our results suggest that the regenerative potential of pericytes depends on their tissue origin, which is an important consideration for future studies.
\end{abstract}

Keywords: Pericytes, mesenchymal stem cells, tissue engineering, angiogenesis, differentiation, magneticactivated cell sorting.

*Address for correspondence:

Sophie Verrier

AO Research Institute Davos

Clavadelerstrasse 8

CH-7270 Davos Platz

Switzerland

Telephone Number: +41814142448

FAX Number: +41814142288

E-mail: sophie.verrier@aofoundation.org

\section{Introduction}

Regeneration of vascularised tissues such as bone is still a challenge. Many tissue engineering strategies have been focused on co-culture models supporting both neovascularisation and the regeneration of the original tissue. For bone repair various combinations of an endothelial cell source and an osteogenic cell type, e.g. osteoblasts or mesenchymal stem cells (MSCs) have been applied (Duttenhoefer et al., 2013; Fuchs et al., 2009; Herrmann et al., 2014; Scherberich et al., 2007; Seebach et al., 2012; Yu et al., 2008; Zhang et al., 2012; Zhou et al., 2010). Interestingly, it was shown that in such co-cultures MSCs were found at perivascular sites of newly formed vessels and expressed pericyte markers (Duttenhoefer et al., 2013; Goerke et al., 2012; Loibl et al., 2014).

Pericytes are vascular mural cells associated with microvessels. The endothelial cell/pericyte ratio has been determined by electron microscopy and immunohistochemistry staining and is highly variable with e.g. retina 1:1, lung 10:1 (Shepro and Morel, 1993), dermis 12.5:1 (Helmbold et al., 2001) and even smaller numbers of pericytes in skeletal muscle (Shepro and Morel, 1993), and reflects the function of the individual tissue. Pericytes play an important role in vessel stabilisation which is of specific interest for the regeneration and engineering of vascularised tissues. Recent publications have identified various factors and pathways involved in recruitment and retention of pericytes, including angiopoietin 1 or Tie2 (Armulik et al., 2005) platelet derived growth factor B (PDGF-B), angiopoietin 1, Sparc, transforming growth factor- $\beta$ (TGF- $\beta$ ), matrix metalloproteinase 9 , connective tissue growth factor (Ccn2) and semaphorins (Aguilera and Brekken, 2014; Hall-Glenn et al., 2012). Capillary and arteriolar pericytes play an important role in inflammatory processes by guiding extravasating leukocytes towards their target (Stark et al., 2013).

The identification of MSCs and progenitor cells at perivascular sites and the subsequent isolation and characterisation of such cells suggested an additional function of pericytes as multipotent progenitors (Chen et al., 2013; Crisan et al., 2008; da Silva et al., 2008). In these studies, pericytes have been isolated by immunostaining of a panel of markers (CD45-CD34-CD146+) by FACS from various tissue sources, including placenta, adipose tissue, skeletal muscle and brain. In monolayer culture these cells displayed a surface marker profile similar to MSCs, are long-term proliferative and preserve multilineage potential (Crisan et al., 2008). 
In vivo, it was shown that transplanted skeletal muscle-derived pericytes (CD45-CD34-CD56-CD146+) promoted repair in ischemic heart disease (Chen et al., 2013). Interestingly, lineage tracking of transplanted cells revealed that only a minor fraction of cells was involved in the actual replacement of cardiomyocytes. Thus, paracrine effects and cellular interactions of transplanted pericytes promoted tissue recovery; observations that resemble the trophic effects attributed to MSCs (Caplan, 2009). Another study comparing CD45-CD34-CD146+ pericytes isolated from adipose tissue stromal vascular fractions (SVF) with unsorted SVF, demonstrated an even higher efficiency in bone formation in an ectopic, intramuscular model for bone repair (James et al., 2012). Recently, a CD146+CD34-CD45-CD56-CD117- pericyte population could be isolated from human myocardium, showing the function to support microvascular structures as well as the potential to differentiate toward osteogenic, adipogenic and chondrogenic lineages (Chen et al., 2015). In contrast to skeletal muscle pericytes, myocardial pericytes were not able to differentiate towards the myogenic lineage suggesting that pericyte functions are dependent on the tissue origin (Chen et al., 2015).

The identification of pericytes remains challenging since the expression of surface markers depends on various factors, such as the tissue type, vessel type, quiescent or angiogenic stages of the vasculature as well as pathological conditions (Diaz-Flores et al., 2009). Besides CD146, proposed markers include neural glial 2 (NG-2), CD146, PDGF and its receptor, $\alpha$ smooth muscle actin ( $\alpha$ SMA), desmin, nestin, endosialin, vascular cell adhesion molecules-1 (VCAM-1) and 3G5 (for a complete list see Diaz-Flores et al., 2009).

Although recent publications have shown promising results, the pericyte-associated regenerative mechanisms are not fully understood. Pericytes may support tissue repair by a paracrine mechanism, by differentiation and integration into the host tissue, and/or by supporting the neovascularisation of the diseased area. Further experiments studying functional parameters in vitro and in vivo are required, as is exploring possible tissue-specific function of pericytes.

The combined function of pericytes in tissue regeneration and vascularisation is of particular interest for the repair and engineering of vascularised tissues. This prompted us to investigate pericytes as a source of cells for tissue engineering and cell therapies. Since a minimal manipulative cell isolation procedure is a major consideration for the clinical applicability of cells, we here used magnetic-activated cell sorting $\left(\mathrm{MACS}^{\circledR}\right)$ as a clinically approved method of cell selection. Pericytes from different tissue are highly heterogeneous; therefore, we studied cells isolated from two different tissue sources, namely human adipose tissue (AT) and bone marrow (BM), and compared them with the respective full MSC populations as well as with two standardised commercially available pericyte types, retinal and placenta pericytes.

\section{Material and Methods}

Isolation of mononuclear cells (MNCs) from human bone marrow aspirate and MSC culture

Bone marrow (BM) aspirates were obtained from the vertebrae of healthy human donors undergoing routine orthopaedic surgery after informed consent and approval by the local ethic committees (KEK Bern 126/03 and EK Regensburg 12-101-0127). The mean age was $54.5 \mathrm{y}$, range 35-76 y; 2 male and 2 female donors were used. $\mathrm{BM}$ aspirates were diluted 1:4 with phosphate-buffered saline (PBS), layered onto Ficoll (Histopaque-1077, Sigma-Aldrich, Buchs, Switzerland) and centrifuged at $800 \times g$ for $20 \mathrm{~min}$ at room temperature. The MNC interphase was collected, washed with aMEM (Gibco, Thermo Fisher Scientific, Zurich, Switzerland) containing PenStrep (100 U/mL, Gibco), $10 \%$ foetal bovine serum (FBS, Seraplus, Pan, Herzogenrath, Germany) followed by 15 min centrifugation at $400 \times g$. The cell count was determined and cells used for MACS ${ }^{\circledR}$ enrichment of pericytes (see below) or cultured for adhesion selection of MSCs. For the latter, MNCs were seeded at a density of 50,000 cells per $\mathrm{cm}^{2}$ with $\alpha$ MEM containing $10 \%$ FBS, PenStrep and $5 \mathrm{ng} / \mathrm{mL}$ basic fibroblast growth factor (bFGF, R\&D Systems, Bio-Techne, Abingdon, UK). After $4 \mathrm{~d}$, non-adherent cells were removed and monolayer-selected MSCs expanded with medium changes every $3 \mathrm{~d}$. When $80 \%$ confluence was reached, cells were detached using $0.5 \%$ trypsin-EDTA (Gibco) and reseeded at a density of 3,000 cells $/ \mathrm{cm}^{2}$. All experiments were performed with cells between passages 2-3.

\section{Isolation of SVF from human adipose tissue}

Abdominal adipose tissue (AT) was harvested from female human donors undergoing plastic surgery $(n=4$, mean age $53.5 \mathrm{y}$, range 46-69 y). Written informed consent of the patient and approval by the local ethical authorities was given (Basel, EK 78/07). Harvested tissue was transferred to sterile containers and stored at $4{ }^{\circ} \mathrm{C}$ in $\alpha \mathrm{MEM}$ containing $10 \%$ FBS, PenStrep $(100 \mathrm{U} / \mathrm{mL})$ until dissection within $24 \mathrm{~h}$. Adipose tissue was detached from surrounding fibrotic and skin tissue, washed in PBS and minced into small pieces. Digestion of tissue was performed by incubation with an equal volume of collagenase type II (Sigma-Aldrich, used at $1 \mathrm{mg} / \mathrm{mL}$ in DMEM containing $4.5 \mathrm{~g} / \mathrm{L}$ glucose (Gibco) and with addition of $3.5 \%$ bovine serum albumin (Sigma-Aldrich)). During the $45 \mathrm{~min}$ of incubation time, tissue was kept on a rocker at $37{ }^{\circ} \mathrm{C}$. Digested tissue was centrifuged at $700 \times g$ for $10 \mathrm{~min}$, the supernatant removed and the cell pellet resuspended in PBS containing $5 \mathrm{mM}$ EDTA. Cells were subsequently filtered through $100 \mu \mathrm{m}$ and $70 \mu \mathrm{m}$ cell strainers and centrifuged again at $700 \times g$ for $10 \mathrm{~min}$. The pellet was resuspended in ACK lysis buffer (155 mM ammonium chloride, $10 \mathrm{mM}$ potassium bicarbonate, $0.1 \mathrm{mM}$ EDTA) for erythrocyte lysis. After 10 min incubation, cells were washed in PBS/ EDTA and spun down at $700 \times g$ for $10 \mathrm{~min}$. The cell pellet, referred to as stromal vascular fraction (SVF), was resuspended in $\alpha$ MEM containing PenStrep and $10 \%$ FBS 
and cell count determined. SVF were either subjected to MACS ${ }^{\circledR}$ enrichment of pericytes or seeded at a density of 3,000 cells $/ \mathrm{cm}^{2}$ in $\alpha$ MEM containing $10 \%$ FBS, PenStrep and $5 \mathrm{ng} / \mathrm{mL}$ bFGF for adherence selection of MSCs. After $4 \mathrm{~d}$, non-adherent cells were removed and monolayerselected MSCs expanded with medium changes every $3 \mathrm{~d}$. When $80 \%$ confluence was reached, cells were detached using $0.5 \%$ trypsin-EDTA (Gibco) and reseeded at a density of 3,000 cells $/ \mathrm{cm}^{2}$. All experiments were performed with cells between passages 2-3.

\section{Magnetic activated cell sorting $\left(\mathrm{MACS}^{\circledR}\right)$ enrichment of pericytes}

Freshly isolated BM-MNCs $(n=3)$ / AT-SVF $(n=4)$ were centrifuged at $300 \times g$ for $10 \mathrm{~min}$ and resuspended in PBS with $0.5 \%$ bovine serum albumin and $2 \mathrm{mM}$ EDTA (Sigma). Cells were enriched using the MiniMACS ${ }^{\circledR}$ Magnetic Microbead System (Miltenyi Biotec, Bergisch Gladbach, Germany) sequentially using CD34 and CD146specific antibodies, according to the manufacturer's instructions. Pericytes were enriched as CD34 negative (CD34-) and CD146 positive (CD146+) cells; the efficiency of enrichment was confirmed by flow cytometry staining. Note that this enriched cell population does still contain CD45 positive cells which will, however, be excluded by adherence selection. Seeding and cultivation of pericytes was performed as previously described (Crisan et al., 2008). In brief, pericytes were seeded at a density of 20,000 cells $/ \mathrm{cm}^{2}$ on gelatin-coated plates in complete endothelial growth medium (EGM-2 bullet kit, Lonza, Verviers, Switzerland). Confluency was generally reached after 8-10 d, and afterwards cells subcultured with a seeding density of 3,000 cells $/ \mathrm{cm}^{2}$ in DMEM containing $4.5 \mathrm{~g} / \mathrm{L}$ glucose, PenStrep and $20 \%$ FBS. All experiments were performed with cells between passages 2-3.

\section{Cell culture of retinal and placenta pericytes and HUVEC}

Two different commercially available pericyte types have been investigated as a source of mature pericytes: human primary retinal pericytes (R-PC, Cell Systems, Kirkland, WA, USA) and human primary placental-derived pericytes (PL-PC, Promocell, Heidelberg, Germany). Pericytes were cultured in pericyte growth medium (PGM, Promocell) at a seeding density of 3,000 cells $/ \mathrm{cm}^{2}$ and subcultured upon $80 \%$ confluency. Cells were used in passage 5-8. To investigate if the different culture medium applied in this study has a direct effect on the functional properties of pericytes, R-PCs were cultured 2 weeks (2 passages) before characterisation in different media (PGM, EGM-2, aMEM $10 \%$ FBS 5 ng/mL bFGF, DMEM 4.5 g/L glucose $20 \%$ FBS).

Green fluorescent protein (GFP)-expressing HUVECs (GFP-HUVECs, Angio-Proteomie, Boston, MA, USA) were cultured on coated plates (Speed Coating Solution, PELObiotech, Martinsried, Germany) in complete EGM2 growth medium at a seeding density of 5,000 cells $/ \mathrm{cm}^{2}$ and subcultured upon $80 \%$ confluency. Cells were used in passage 7-9.

\section{Flow cytometry}

Cells were analysed for expression of pericyte markers (negative: CD45, CD34; positive: CD146, NG2, PDGFR $\beta$ ) and selected mesenchymal stem cell markers (CD44, CD73, CD 90, CD105) by flow cytometry. For immunolabelling, 100,000-200,000 cells were stained with the following antibodies alone or in different combinations: CD34-PE, CD44-APC, (both Miltenyi Biotech), CD73PeCy7, CD146-PeCy7, CD105-PE, CD45-APC, CD90BV421, mouse anti human IgG1-PeCy7 (BD Bioscience, Allschwil, Switzerland) and incubated for $30 \mathrm{~min}$ on ice according to the manufacturer's recommendations. Cells were washed in PBS before analysis using a BD FACS Aria III (BD Bioscience). At least 25,000 events were recorded per sample. Data analysis was performed using BD FACSDiva software (BD Bioscience) and a gating strategy used to exclude cell doublets.

\section{Differentiation}

For osteogenic differentiation cells were seeded in triplicates at a density of 20,000 cells $/ \mathrm{cm}^{2}$ on Thermanox coverslips (Thermo Fisher Scientific) in 24-well tissue culture plates and were either incubated in control medium (DMEM 1 g/L glucose, $10 \%$ FBS (Seraplus, Pan)) or osteogenic differentiation medium (DMEM $1 \mathrm{~g} / \mathrm{L}$ glucose, $10 \% \mathrm{FBS}, 50 \mu \mathrm{g} / \mathrm{mL}$ ascorbic acid, $5 \mathrm{mM}$ glycerol-2-phosphate, $10 \mathrm{nM}$ dexamethasone (all substances purchased from Sigma-Aldrich)). Cells were cultured for $21 \mathrm{~d}$ with three media changes per week. Mineral deposition was examined by alizarin red staining. For the staining, wells were washed twice with PBS and cells fixed for 15 min with $4 \%$ formaldehyde. After three washes with demineralised water, cells were stained with a $40 \mathrm{mM}$ Alizarin Red S solution (Sigma-Aldrich) for $60 \mathrm{~min}$. Excess stain was removed by repeated washing with demineralised water and staining visualised using an Axiovert40 CFL microscope (Zeiss).

For adipogenic differentiation cells were seeded in triplicates at a density of 16,000 cells $/ \mathrm{cm}^{2}$ in $24-w e l l$ plates and incubated either in control medium (DMEM $4.5 \mathrm{~g} / \mathrm{L}$ glucose, $10 \% \mathrm{FBS}$ ) or adipogenic differentiation medium (DMEM 4.5 g/L glucose, $10 \%$ FBS (Seraplus, Pan), $5 \mu \mathrm{g} / \mathrm{mL}$ insulin, $1 \mu \mathrm{M}$ dexamethasone, $0.5 \mathrm{mM}$ isobutylmethylxanthine, $60 \mu \mathrm{M}$ indomethacine); medium was changed 3 times per week. After 2 weeks, wells were washed, fixed and stained with Oil Red O solution (SigmaAldrich) to visualise lipid droplets. Stained plates were observed using an Axiovert40 CFL microscope.

To compare osteogenic and adipogenic differentiation efficiency between the different cells types, stained wells were scanned using an $\operatorname{EVOS}^{\circledR}$ FL Auto Cell Imaging System (Thermo Fisher Scientific) and the percentage of stained area calculated in ImageJ (Rasband, NIH, Bethesda, MD, USA) using an individual threshold.

For chondrogenic differentiation, cells were cultured as pellets of 250,000 cells for 3 weeks in chondrogenic medium (DMEM $4.5 \mathrm{~g} / \mathrm{L}$ glucose, $50 \mu \mathrm{g} / \mathrm{mL}$ ascorbic acid, $100 \mathrm{nM}$ dexamethasone, $1 \%$ ITS (Corning, Amsterdam, Netherlands), $1 \%$ non-essential amino acids (NEAA, Gibco) and $10 \mathrm{ng} / \mathrm{mL}$ TGF- $\beta 1$ (Fitzgerald Industries International, Acton, MA, USA)) with medium changes 

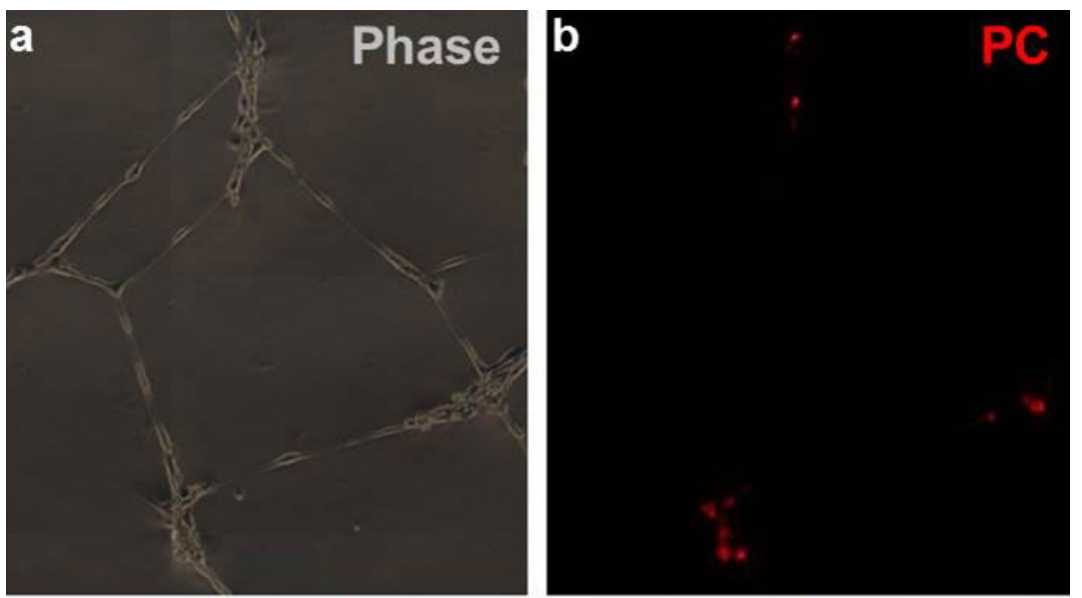

Fig. 1. Matrigel ${ }^{\mathrm{TM}}$ image analysis. Image analysis method of Matrigel ${ }^{\mathrm{TM}}$ co-seeded with PKH26-red labelled pericytes (10\%) and GFP-HUVECs (90\%). a) Representative phase contrast image taken after $24 \mathrm{~h}$ of incubation, b) shows the red labelled pericytes, and c) shows GFP- labelled HUVECs. d) Tubular structures are marked with the polygon lines (grey) and nodes are surrounded by circles (yellow). Scale bar $=100 \mu \mathrm{m}$.
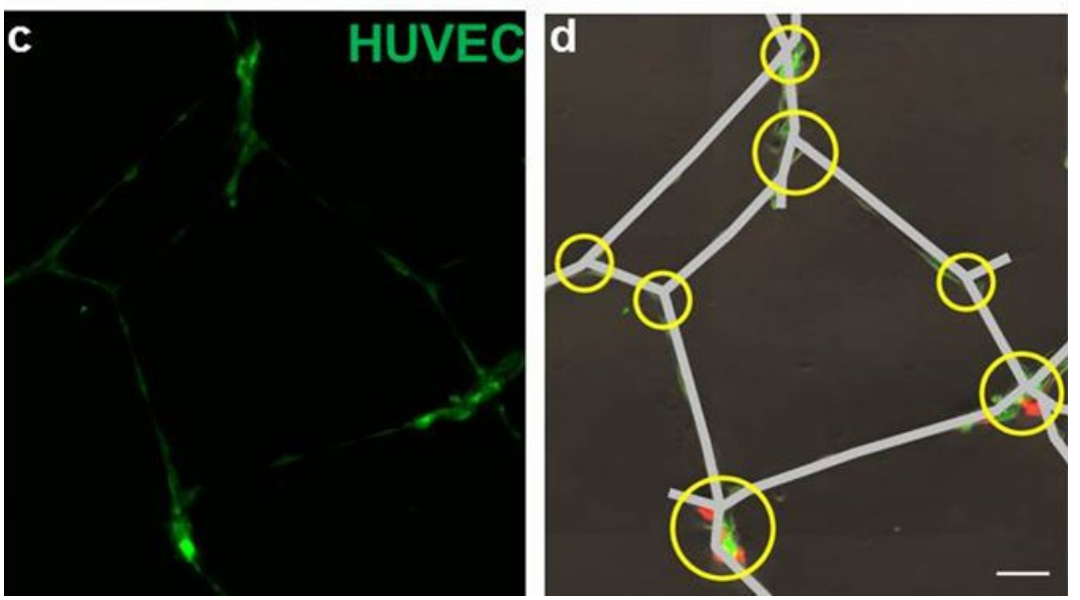

three times per week. Pellets were fixed in $70 \%$ methanol for at least $24 \mathrm{~h}$, incubated in $5 \%$ sucrose in PBS overnight, frozen in tissue freezing medium (Leica Microsystems, Heerbrugg, Switzerland) and $10 \mu \mathrm{m}$ thick cryosections were prepared. Safranin O-Fast Green Staining was performed on cryosections to detect deposition of glycosaminoglycans and pictures taken using an Axioplan2 microscope equipped with an AxioCamHRc camera and AxioVision software (Zeiss, Feldbach, Switzerland).

\section{Matrigel $^{\mathrm{TM}}$ assay}

For Matrigel ${ }^{\mathrm{TM}}$ assays, pericytes were labelled with PKH26-red cell tracker (Sigma-Aldrich) according to the manufacturer's protocol. Labelled pericytes $(10 \%)$ were co-seeded with GFP-HUVECs $(90 \%)$ in two-well Nunc Lab-Tek ${ }^{\text {TM }}$ Chamber Slides (Thermo Fisher Scientific) coated with a thin layer of Matrigel ${ }^{\mathrm{TM}}$ (growth factor reduced, $\mathrm{BD}$ Bioscience) at a seeding density of 30,000 cells/well in EGM-2 medium. Microscopic analysis was performed $1 \mathrm{~h}$ and $24 \mathrm{~h}$ after seeding using an Axiovert 200m microscope equipped with an AxiocamHRc and Axiovision software (Zeiss). A montage of 12 images (3 by 4 images, total area $2 \times 2 \mathrm{~mm}$ ) taken in the centre of each well was assembled from individual images at $10 \times$ objective (pixel size $0.63 \mu \mathrm{m}$ ) using the Mosaix module. The same areas were additionally imaged with phase contrast (Fig. 1a). The PKH26-red labelled pericytes (Fig. 1b) were imaged with the Zeiss filter set \#15 (excitation band pass $546 \pm 12 \mathrm{~nm}$, beam splitter 580, emission long pass 590, standardised exposure time) and GFP-HUVECs (Fig. 1c) with filter set \#10 (excitation band pass 450$490 \mathrm{~nm}$, beam splitter 510, emission band pass 515-565, standardised exposure time). All three images generated with different techniques of the same area from the same well were combined in one file. The image analysis started by surrounding every node with a (yellow) circle and every tubular structure was marked with a (grey) polygon line (55 $\mu \mathrm{m}$ thickness) as shown in Fig. 1d. The number and area of the two regions of interests, namely the tubular structures (lines) and branching points (circles), were measured. The image analysis was performed with the KS400 software (Zeiss) and a custom made macro. An individual threshold was set for the images of the red-labelled pericytes and GFP-HUVECs and the area of the respective fluorescent dye within the regions of interests calculated. Data obtained from Matrigel ${ }^{\mathrm{TM}}$ seeded with HUVECs alone was used to normalise for inter experimental variation.

\section{Statistical analysis}

Statistical analysis of data was performed using Prism software (GraphPad Software, La Jolla, CA, USA). We assumed normal distribution of data. Either one-way or two-way ANOVA with Tukey's multiple comparison test were applied to test for significant differences between experimental groups. Data presented are means \pm standard error of the mean (SEM) unless stated otherwise. 


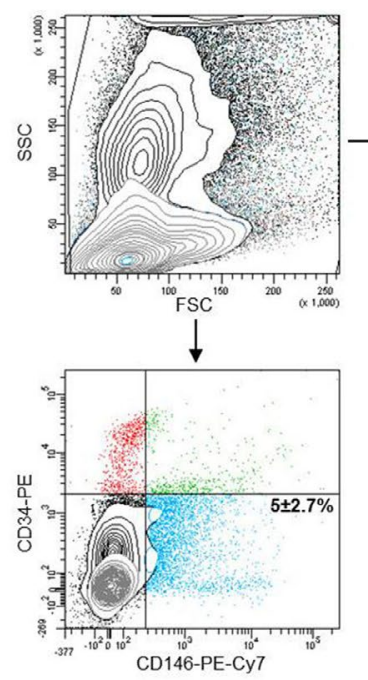

C

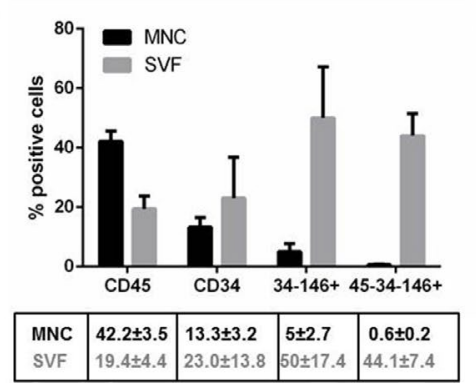

Mononuclear Cells

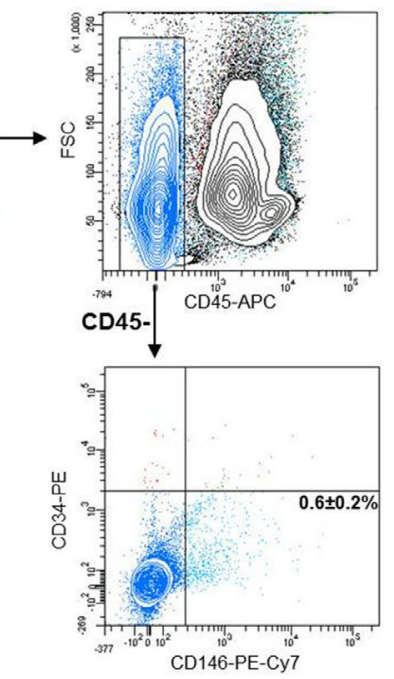

d

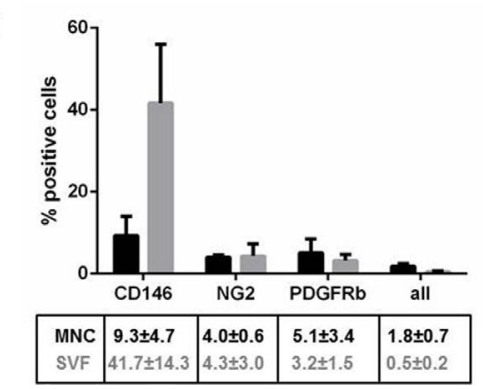

Stromal Vascular Fraction

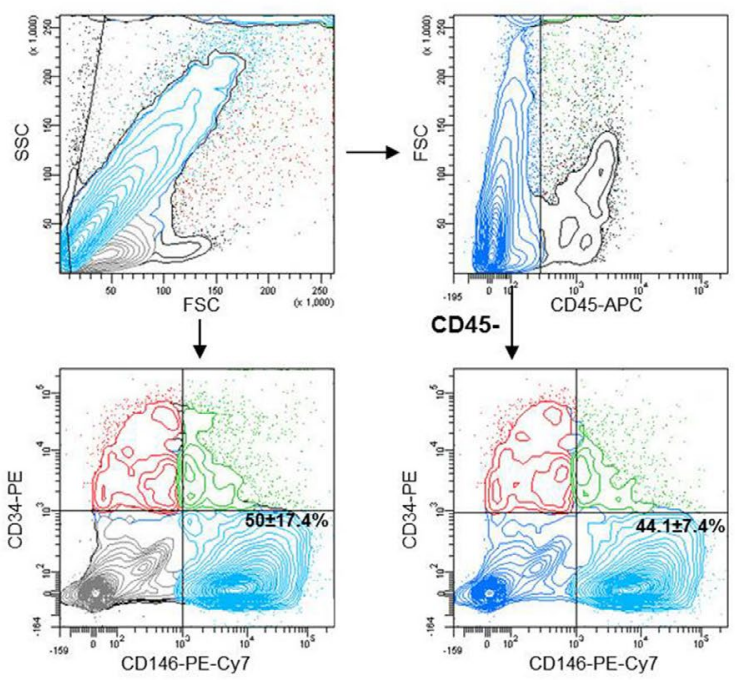

e

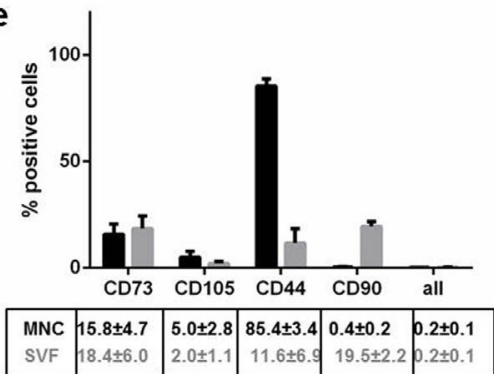

Fig. 2. Surface marker expression on MNCs and SVF. Flow cytometry analysis of MNCs and SVF after antibody staining. (a-b) MNCs (a) and SVF (b) were identified by forward scatter (FSC) - site scatter (SSC) profile and CD34/CD146 positive cells detected within the full cell population or the CD45- cell population. (c-e) Quantitative analysis of FACS results. $n=4$. Error bars indicate SEM.

\section{Results}

\section{Abundance and enrichment of pericytes in SVF and within the MNC population}

It has been described by the Peault group that pericytes may be isolated from various human tissues as CD45CD34-CD146+ cells (Crisan et al., 2008). We show that such a cell population represents $0.6 \pm 0.2 \%$ of BM-MNCs and $44.1 \pm 7.4 \%$ of AT-SVF (Fig. 2a-c). We also tested the expression of NG-2 and PDGFR $\beta$, which represent additional putative pericyte markers. We found $4.3 \pm 3.0 \%$ NG-2 and $3.2 \pm 1.5 \%$ PDGFR $\beta$ positive cells in the SVF. In $\mathrm{BM}$ we detected $4 \pm 0.6 \% \mathrm{NG}-2$ and $5.1 \pm 3.4 \%$ PDGFR $\beta$ expressing MNCs (Fig. 2d). The percentage of cells expressing all three pericyte markers (CD146, NG-2 and PDGFR $\beta$ ) was $0.5 \pm 0.2 \%$ of the SVF and $1.8 \pm 0.7 \%$ of BM-MNCs.

Next, we analysed the expression of typical MSC markers. Due to the absence of CD105 expression on MNCs and SVFs and the absence of CD44 on fresh BMMSCs, only a minor population $(0.2 \%)$ of BM-MNCs and SVF expressed the full panel of surface markers (CD44, CD73, CD90 and CD105) characteristic for in vitro cultured MSCs (Fig. 2e).

We applied MACS ${ }^{\circledR}$ to enrich CD34-CD146+ cells, after separation purity of the enriched cell population was assessed by flow cytometry (Fig. 3a-d). For BM-derived cells in average a 20-fold enrichment could be achieved, resulting in a cell population containing $46.7 \pm 11.1 \%$ of CD34-CD146+ cells (Fig. 3c). Most of these cells co-expressed CD45, resulting in a small percentage of CD45-CD34-CD146+ cells (7.2 $\pm 2.9 \%)$. MACS ${ }^{\circledR}$ of ATSVF yielded a cell population containing $82.5 \pm 9.0 \%$ CD34-CD146+ and 76.5 $\pm 7.0 \%$ CD45-CD34-CD146 cells (Fig. 3d).

\section{Growth kinetic and surface marker profile of pericytes from different tissue sources}

The population doubling time of pericytes from BM and AT was calculated after the first passage of adherent colonies. The full plastic adherent cell population from BM and AT both displayed fast population doubling times (Fig. 3e), with AT-MSCs showing a slightly lower doubling time $(0.97 \pm 0.08 \mathrm{~d})$ compared to BM-MSCs $(1.34 \pm 0.13 \mathrm{~d})$. In contrast, population doubling time was longer in AT$\mathrm{PC}(1.78 \pm 0.51 \mathrm{~d})$ and BM-PC $(3.19 \pm 0.60 \mathrm{~d}, p<0.01)$ in comparison to the respective full AT or BM-MSC population (Fig. 3e).

The expression of a panel of surface markers typical for MSCs (CD44, CD90, CD73 and CD105) and pericytes (CD146, NG-2 and PDGFR $\beta$ ) was assessed by antibody staining and flow cytometry (Table 1). Results show differential expression of markers on pericytes from different tissue source. Of note, the expression of CD146 
a

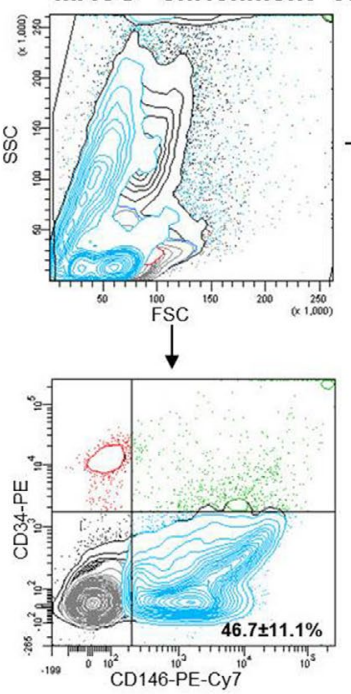

C

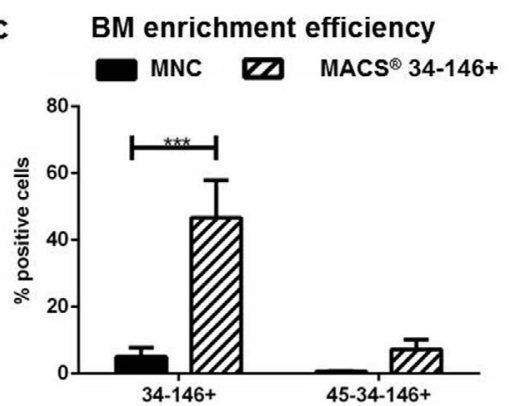

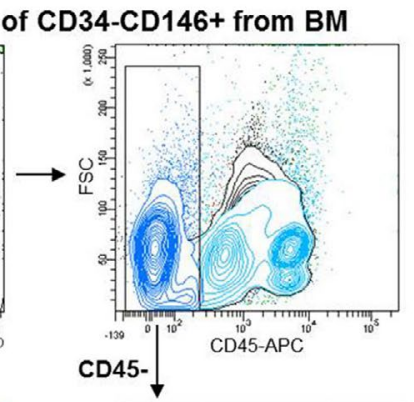

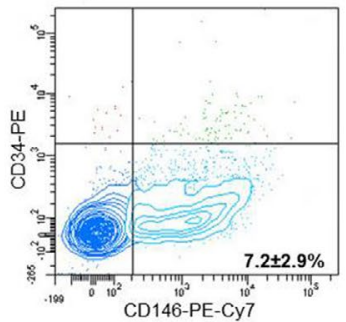

b

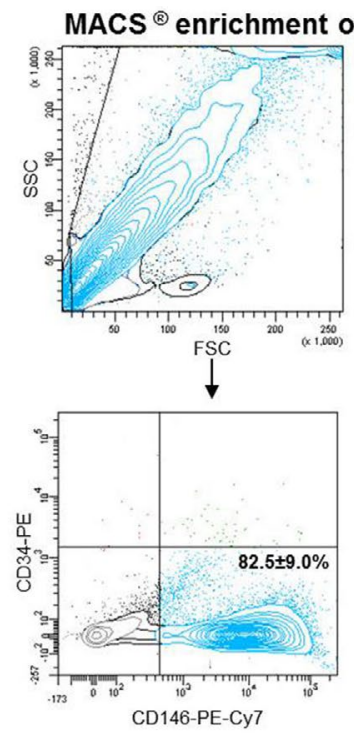

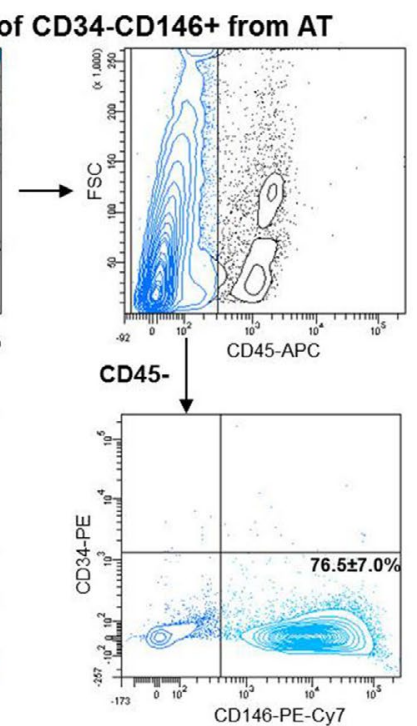

d AT enrichment efficiency e

Population doubling time
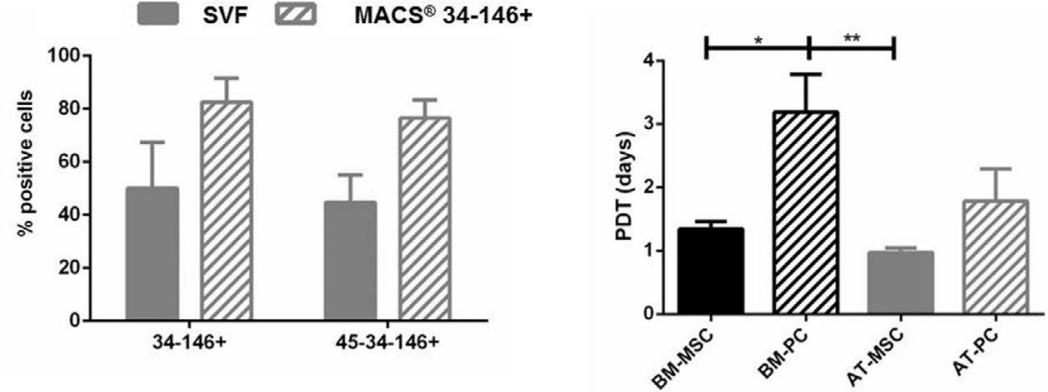

Fig. 3. Cell enrichment and growth kinetics. Flow cytometry analysis of cells after MACS ${ }^{\circledR}$ enrichment of CD34CD146+ cells stained with anti-CD45, CD34 and CD146 antibodies. Cells derived from MNCs (a, c) and SVF (b, d) were identified by forward scatter (FSC) - site scatter (SSC) profile and CD34/CD146 positive cells detected within the full cell population or the CD45- cell population. (e) Population doubling time in monolayer culture. Note that cells were expanded in different growth media according to previous publications: PCs: EGM-2/DMEM-20 \% FBS (Crisan et al., 2008); MSCs: $\alpha$ MEM-10 \% FBS + bFGF (Martin et al., 1997). $n=3$. Error bars indicate SEM.

Table 1. Cell surface marker expression after in vitro culture.

\begin{tabular}{|l|c|c|c|c|c|c|}
\hline & R-PC & PL-PC & BM-MSC & BM-PC & AT-MSC & AT-PC \\
\hline CD146 & $22.0 \pm 5.1$ & $85.3 \pm 8.3$ & $95.0 \pm 2.7$ & $91.9 \pm 7.6$ & $91.7 \pm 2.2$ & $84.0 \pm 11.5$ \\
\hline NG-2 & $74.4 \pm 3.6$ & $83.5 \pm 16.2$ & $81.4 \pm 5.7$ & $90.0 \pm 4.9$ & $88.3 \pm 4.5$ & $83.5 \pm 11.0$ \\
\hline PDGFR & $3.1 \pm 1.0$ & $3.8 \pm 1.7$ & $93.8 \pm 2.3$ & $92.5 \pm 1.3$ & $76.5 \pm 11.4$ & $63.3 \pm 10.3$ \\
\hline CD44 & 100 & $100 \pm 0.1$ & 100 & 100 & $99.9 \pm 0.1$ & $99.3 \pm 0.5$ \\
\hline CD90 & $93.1 \pm 4.1$ & $87.6 \pm 2.3$ & $96.9 \pm 3.0$ & $92.7 \pm 6.2$ & $99.4 \pm 0.3$ & $90.8 \pm 5.8$ \\
\hline CD73 & 100 & $99.8 \pm 0.2$ & 100 & $99.9 \pm 0.1$ & $99.6 \pm 0.3$ & $99.7 \pm 0.1$ \\
\hline CD105 & $88.2 \pm 9.2$ & $85.2 \pm 4.3$ & 100 & $99.7 \pm 0.1$ & $99.1 \pm 0.3$ & $99.5 \pm 0.1$ \\
\hline CD146+NG-2+PDGFRP+ & $1.3 \pm 0.5$ & $3.6 \pm 1.8$ & $61.4 \pm 20.8$ & $79.8 \pm 3.9$ & $66.5 \pm 12.3$ & $48.3 \pm 2.9$ \\
\hline CD44+CD90+CD73+CD105+ & $83.0 \pm 9.0$ & $74.3 \pm 4.6$ & $96.9 \pm 3.0$ & $92.2 \pm 6.1$ & $99 \pm 0.4$ & $90.3 \pm 6.1$ \\
\hline
\end{tabular}

(1) Expression of pericyte markers CD146, NG-2 and PDGFR $\beta$ and MSC markers CD44, CD73, CD90 and CD105 was assessed by antibody staining and flow cytometry (given as \% of positively stained cells). Depicted are mean values \pm SEM.

(2) While all tested cell types stained positive for the MSC markers, only BM- and AT-derived cells were triple positive for all pericytes markers. PL-PC and R-PC showed high expression of NG-2 but CD146 and PDGFR $\beta$ were absent or detected only on a subpopulation of cells. 

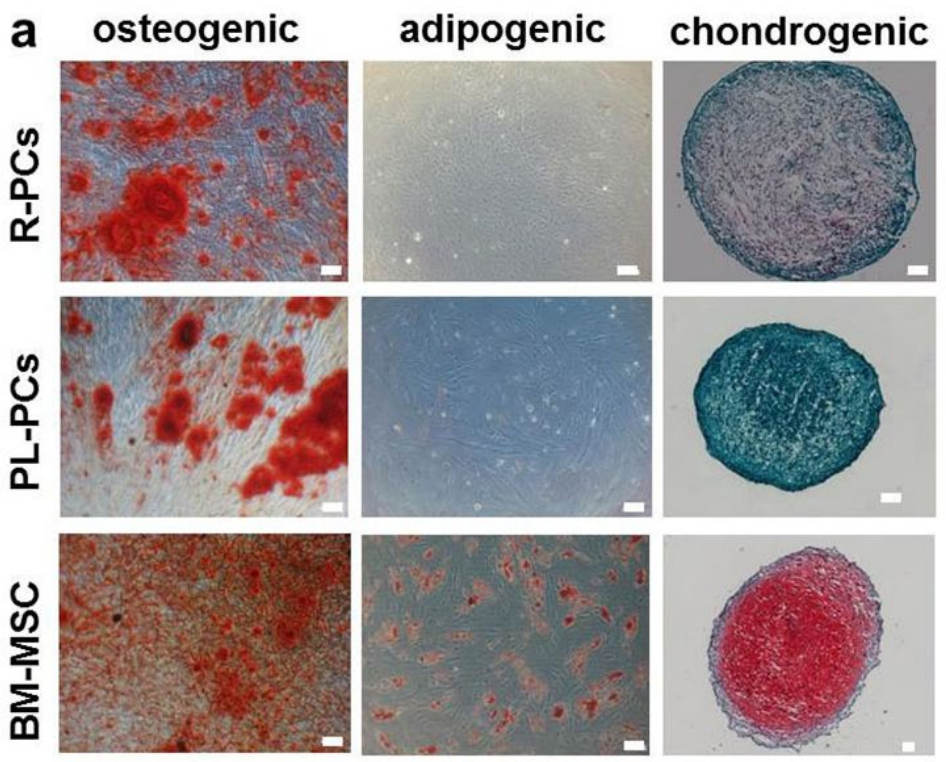

b
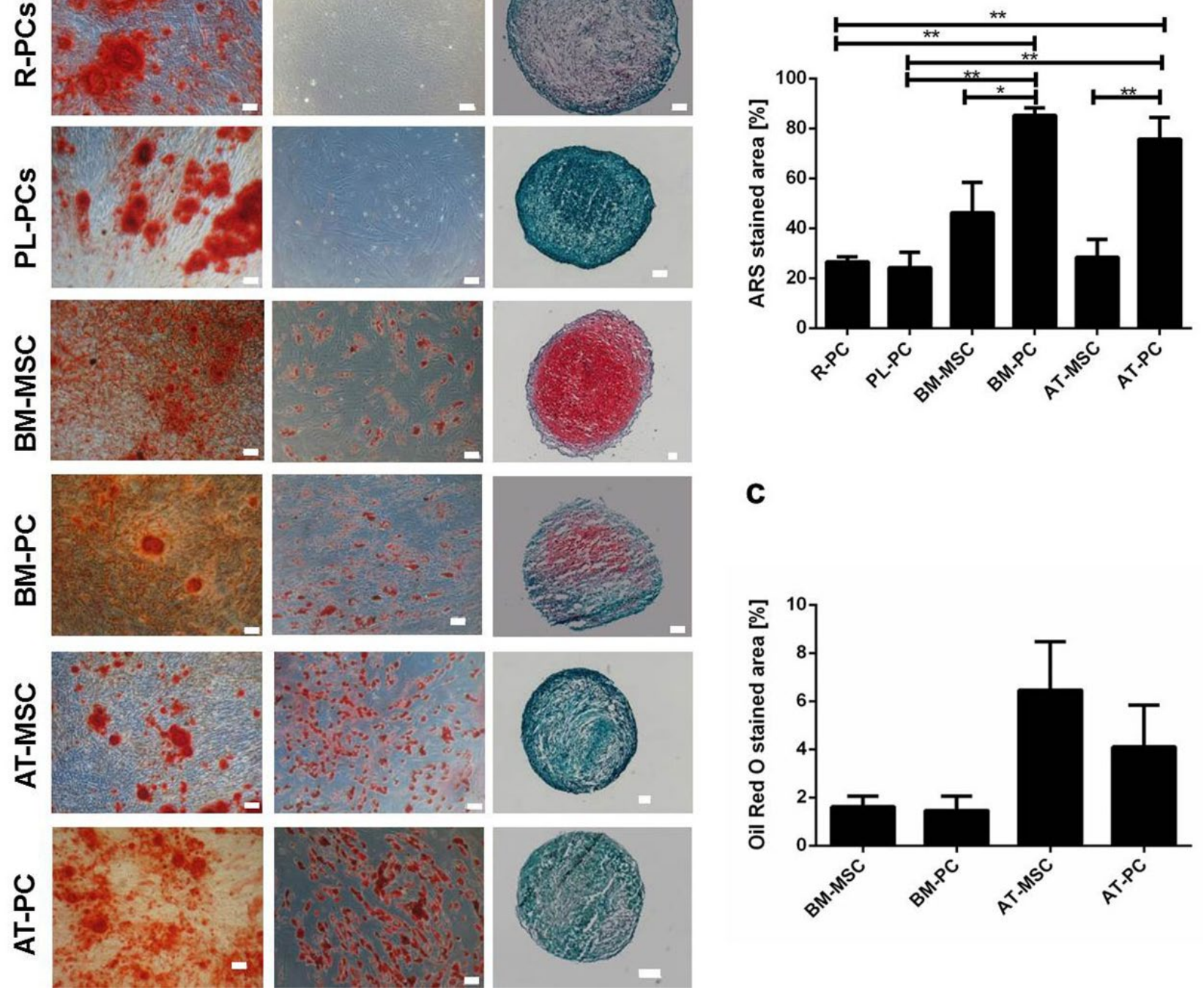

C

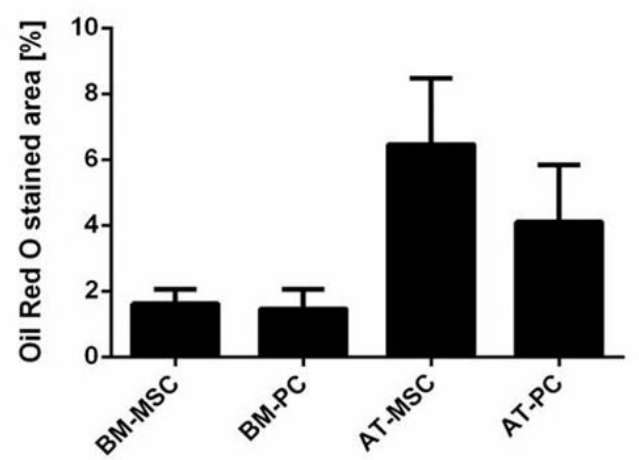

Fig. 4. Multilineage differentiation potential. a) Osteogenic (left column), adipogenic (middle column) and chondrogenic differentiation (right column) of pericytes assessed by Alizarin Red S (ARS), Oil RedO and Safranin O-Fast Green staining, respectively. Only BM-derived cells were able to undergo chondrogenic differentiation observed by pink staining of glycosaminoglycans. Note that R-PC and PL-PC were not able to differentiate towards the adipogenic lineage (indicated by accumulation of red-stained lipid droplets). Mineral deposition (red stain) was observed for all cell types. Pictures of the entire wells were used to quantify the area stained with Alizarin Red S (b) and Oil Red O (c). Depicted are mean values \pm SEM. $* p<0.05 ; * * p<0.01$. Scale bars $=100 \mu \mathrm{m}$.

and PDGFR $\beta$ was variable. BM and AT-derived cells as well as PL-PC were mostly positive for CD146 (range 84$95 \%$ of CD146 positive cells), whilst only $22 \pm 5.1 \%$ of R-PC expressed CD146 $(p<0.001$ compared to all other cell types). The differences were even more pronounced for PDGFR $\beta$, which was almost completely absent in R-PC and PL-PC ( $3.1 \pm 1 \%$ and $3.8 \pm 1.7 \%, p<0.001$ compared to all other cell types), but expressed by a high percentage of adipose-derived cells (AT-MSC: $76.5 \pm 11.4 \%$; ATPC: $63.3 \pm 10.3 \%)$ and the majority of BM-derived cells (BM-MSCs: $93.8 \pm 2.3 \%$; BM-PC: $92.5 \pm 1.3 \%$ ). The different expression levels of CD146 and PDGFR $\beta$ was evident in the percentage of triple positive cells, which was significantly lower in R-PC and PL-PC. Remarkably, no significant differences were observed between full MSC populations from BM and AT and CD34-CD146+ enriched pericytes.

In contrast to the heterogeneous expression of putative pericyte specific markers, the tested panel of positive MSC markers was highly expressed in all tested cell types (Table 1).

\section{Multilineage potential of pericytes from different tissue sources}

Multilineage potential of the different cell types was investigated by testing the ability of cells to differentiate along osteogenic, adipogenic and chondrogenic lineages (Fig. 4a).

Osteogenic differentiation, as assessed by Alizarin Red staining to detect calcium deposition after $21 \mathrm{~d}$, was 
a $10 \%$ R-PC - $90 \%$ HUVEC

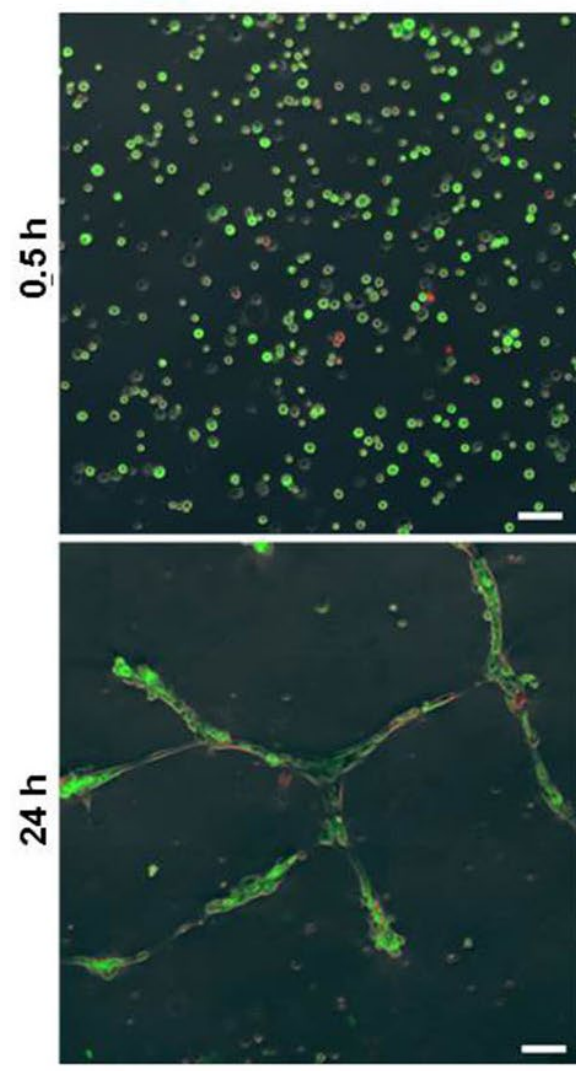

b

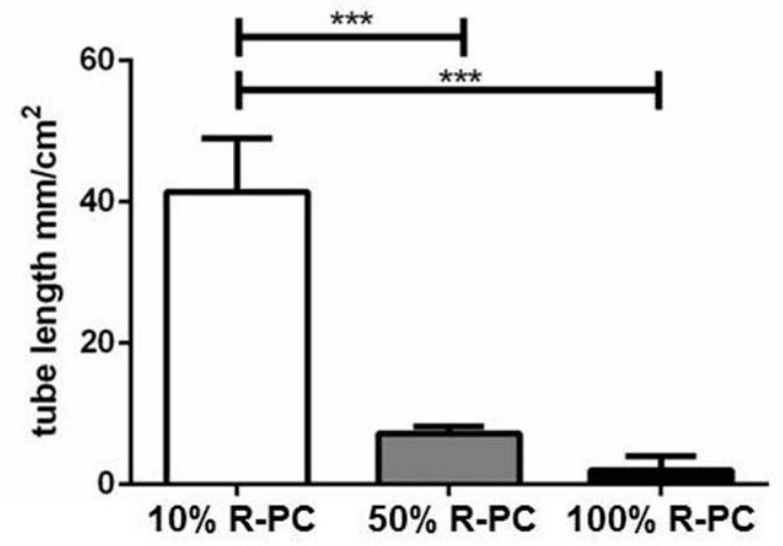

$50 \%$ R-PC - $50 \%$ HUVEC
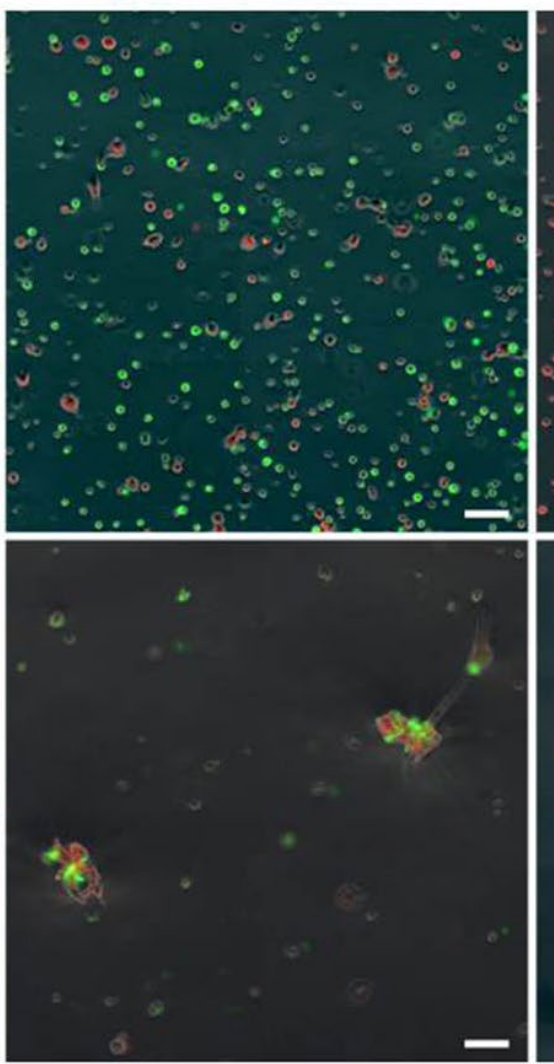

$100 \%$ R-PC
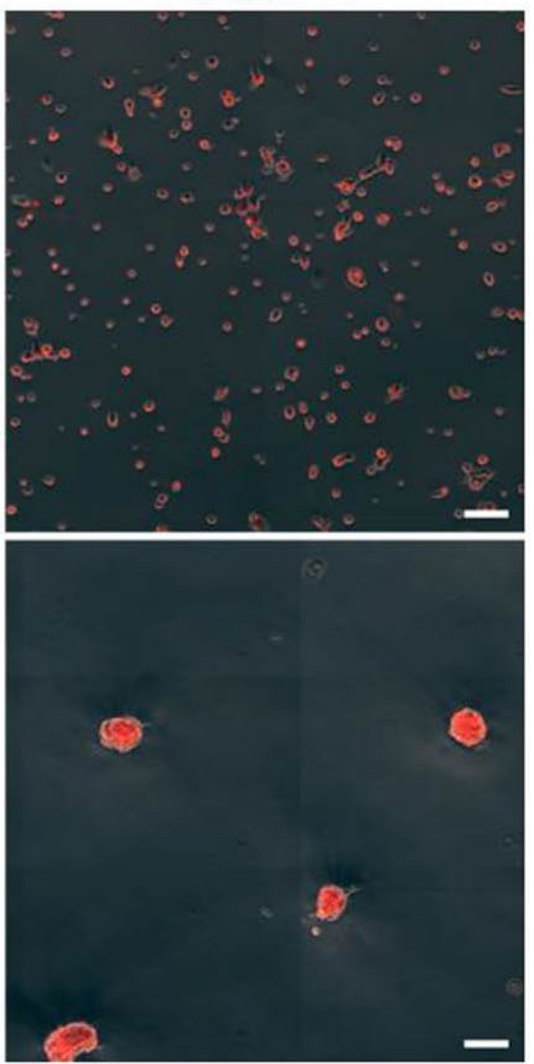

C

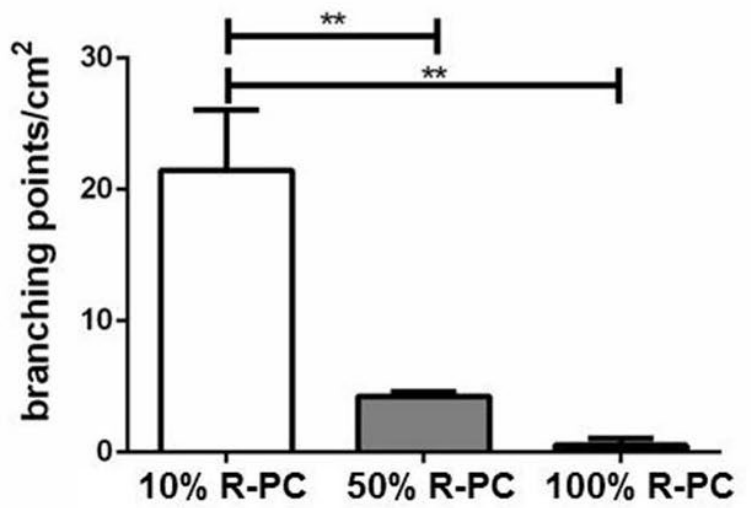

Fig. 5. The influence of pericyte-endothelial cell ratio on network formation on Matrigel $^{\mathrm{TM}}$. A thin layer of growth factor reduced Matrigel ${ }^{\mathrm{TM}}$ was seeded with GFP-labelled HUVECs (green) and/or PKH26-red labelled R-PC at a density of 7,500 cells $/ \mathrm{cm}^{2}$ and observed directly after seeding and after $24 \mathrm{~h}$ of incubation in endothelial growth medium. Representative pictures are shown in (a). Scale bars $=100 \mu \mathrm{m}$. (b-c) Analysis of tube-like structure formation after $24 \mathrm{~h}$ showed that the perciyte-HUVEC ratio had a significant effect on the tube length (b) and the number of branching points (c). Pericyte single culture did not show ability to form tube-like structures. ** $p<0.01 ; * * * p<0.001$.

observed for all cell types (Fig. 4a, left column). Image quantification revealed significant differences in the area covered by Alizarin Red stain (Fig. 4b). BM-PC and AT-PC showed significantly greater areas of Alizarin Red staining compared to the respective full stem cell population (BMPC $85.2 \pm 3.1 \%$, BM-MSC $46.3 \pm 12.1 \%(p<0.05)$; ATPC $75.7 \pm 8.8 \%$, AT-MSC $28.4 \pm 7.2 \%(p<0.01))$. R-PC and PL-PC showed the lowest values with $26.7 \pm 2 \%$ and $24.3 \pm 6.2 \%$ of the total surface area positively stained for Alizarin Red, respectively. Furthermore, Alizarin Red staining was more pronounced in BM-derived cultures compared to AT-derived cells, although the difference did not reach statistical significance.

When cells were incubated in adipogenic differentiation medium, formation of lipid droplets was detected after 2 weeks in all BM and AT-derived cells (Fig. 4a, middle column). Measurements of the Oil Red O-stained area indicated that the differentiation efficiency was reflected by the tissue of origin, with AT-derived cells showing greater Oil Red O staining compared to BM-derived cells (Fig. 4c). 
a
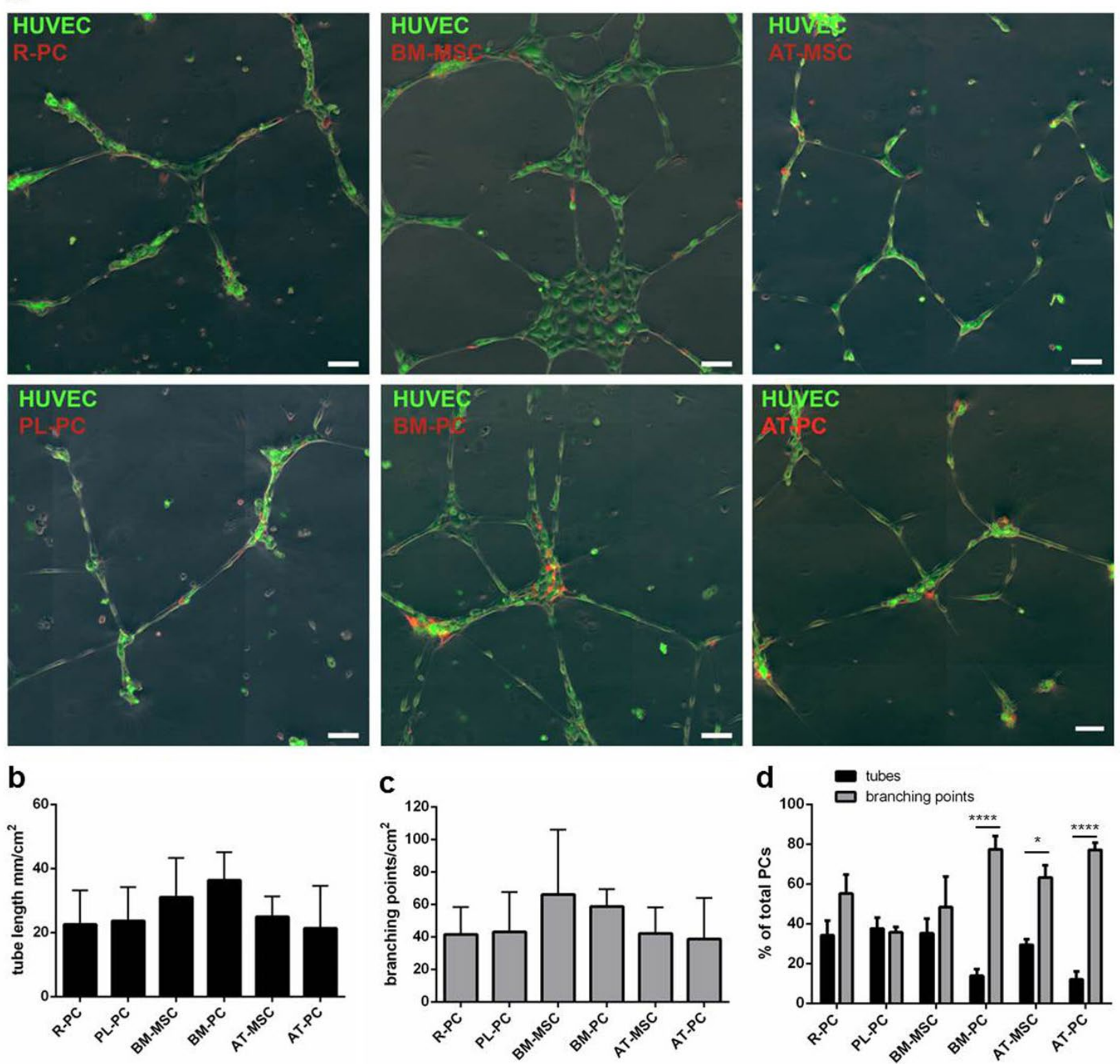

Fig. 6. Angiogenic potential of pericytes from different tissue sources. (a) GFP-HUVECs were co-seeded with red fluorescent (PKH26-red) pericytes on a thin layer of Matrigel ${ }^{\mathrm{TM}}$ at a ratio of 9:1 and incubated in endothelial growth medium. Scale bars $=100 \mu \mathrm{m}$. Length of tube-like structures (b) and number of branching points (a) were analysed after $24 \mathrm{~h}$ by fluorescence microscopy. (d) Pericyte localisation in different regions of interest (tubes or branching points) was analysed by image quantification. Network formation was observed with all tested cell types. Depicted are mean values \pm standard deviation. $* p<0.05 ; * * * * p<0.0001$.

In contrast to AT- and BM-derived cells, R-PC and PL-PC did not show lipid accumulation.

Finally, we assessed the chondrogenic differentiation potential of cells cultured for $21 \mathrm{~d}$ in micromass pellets stimulated with TGF- $\beta 1$. Deposition of glycosaminoglycans was examined on Safranin-O-stained cryosections. The results (Fig. 4a, right column) revealed that only BM-derived cells were able to differentiate along the chondrogenic lineage. Here, chondrogenesis was observed for all tested BM-MSC donors $(n=4)$ but only two out of 4 BM-PC donors.

\section{Pericyte contribution to tube-like structure formation on Matrigel ${ }^{\mathrm{TM}}$}

To assess the angiogenic potential of pericytes we used a Matrigel $^{\mathrm{TM}}$ assay. We first used R-PC to establish the assay. Here, we found that pericytes integrated in tube-like structures on Matrigel ${ }^{\mathrm{TM}}$ when co-seeded in physiological ratios (10\% pericytes) with HUVECs (Fig. 5). In contrast, formation of tube-like structures was significantly lower (tube length and number of branching points) when pericytes were seeded alone or in superficial ratios. Based on these results we used a seeding ratio of $10 \%$ pericytes and $90 \%$ HUVECs to compare pericytes from different 


\section{a Cell morphology}
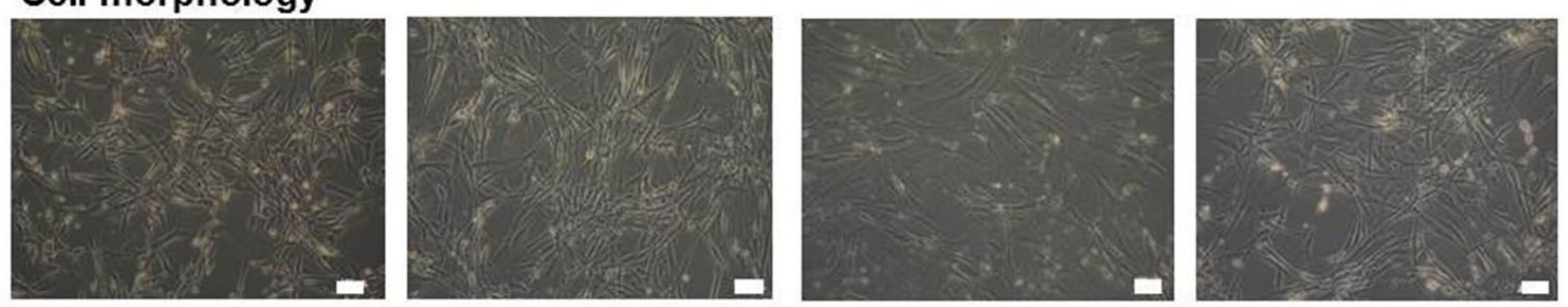

b Multilineage Differentiation potential
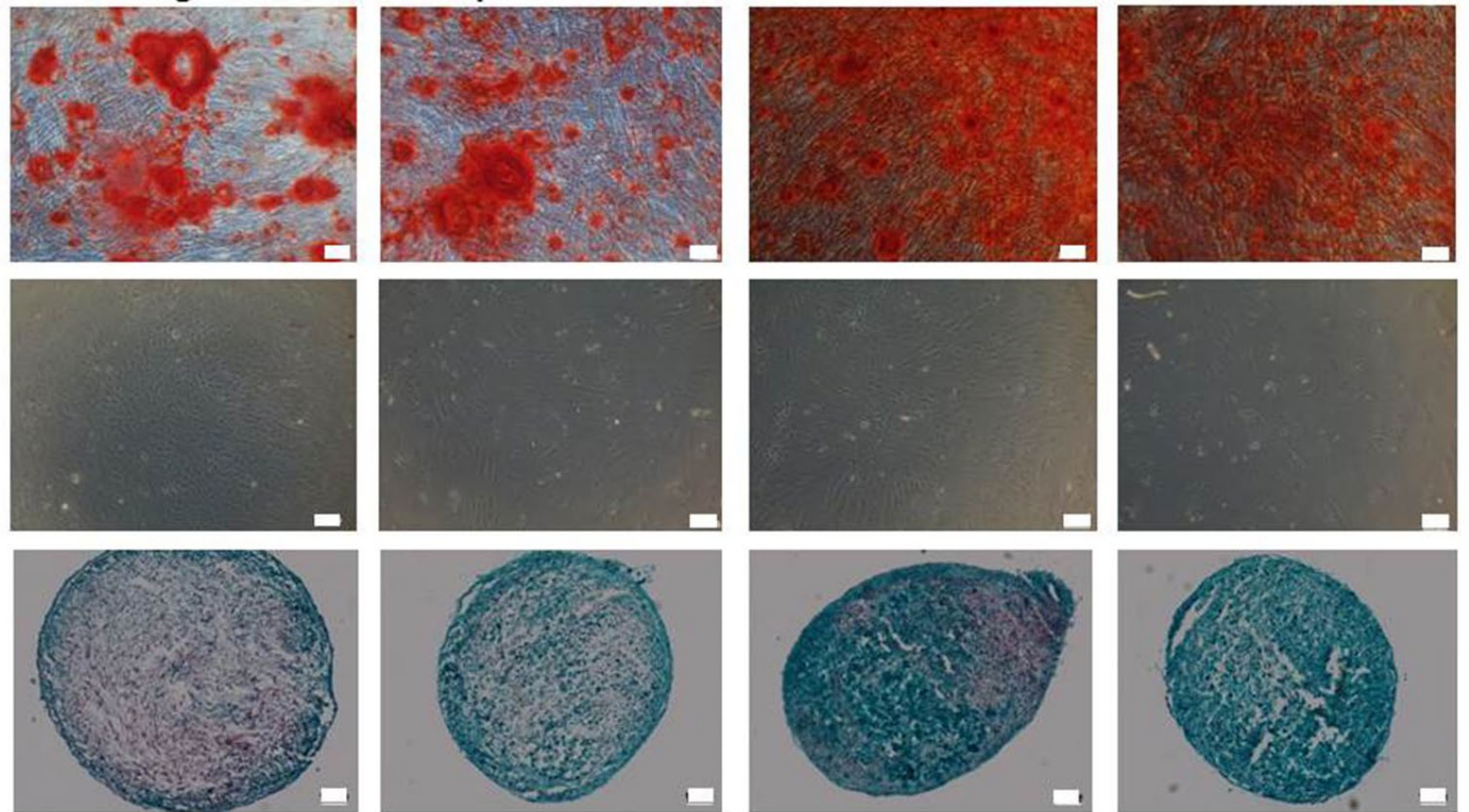

C Matrigel $\mathrm{IM}^{\mathrm{TM}}$
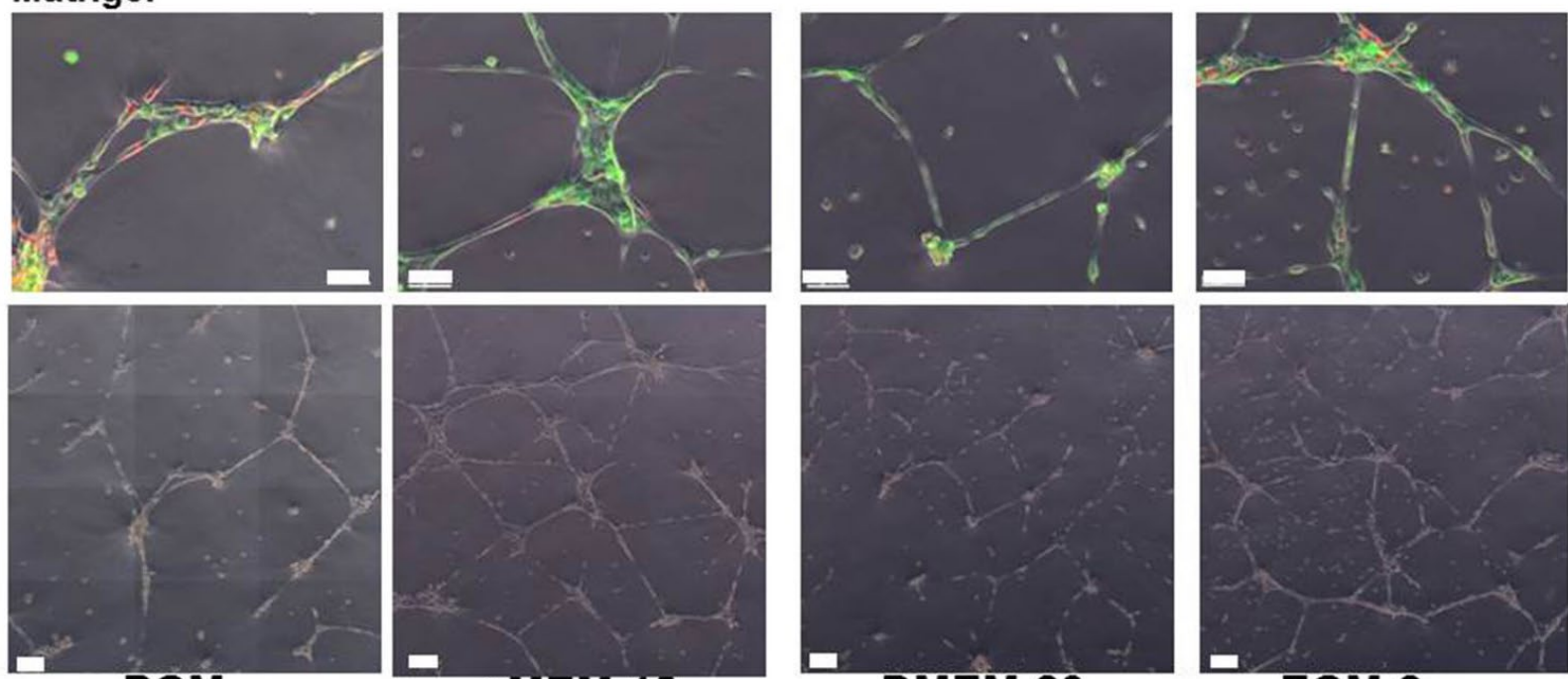

PGM

aMEM-10

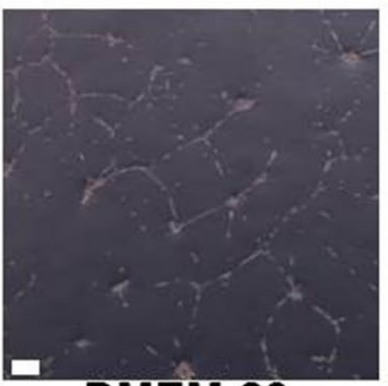

DMEM-20

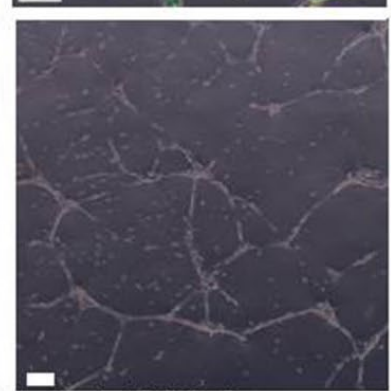

Fig. 7. The influence of different growth medium on the multilineage and angiogenic potential of R-PCs. (a) Phase contrast image of R-PC cultured for 2 weeks in the respective growth medium. (b) Osteogenic (top row), adipogenic (middle row) and chondrogenic differentiation (bottom row) of R-PC assessed by Alizerin Red, Oil Red O and Safranin O-Fast Green staining, respectively. (c) GFP-HUVECs were co-seeded with red fluorescent R-PCs on a thin layer of Matrigel ${ }^{\mathrm{TM}}$ at a ratio of 9:1 and incubated in endothelial growth medium and observed after $24 \mathrm{~h}$ of incubation. High magnification fluorescence pictures are shown in the top row, scale bars $=100 \mu \mathrm{m}$, and overview phase contrast pictures in the bottom, scale bars $=200 \mu \mathrm{m}$. 
tissue sources. We found that all tested cell types integrated into tube-like structures (Fig. 6a). Quantitative analysis did not show any statistically significant differences between groups with regards the length of tube-like structure or the number of branching points (Fig. 6b, c). We further evaluated the localisation of pericytes within tube likestructures. This revealed that virtually all pericytes were incorporated into the networks (Fig. 6d). Interestingly, BMPC as well as AT-derived cells (both AT-MSCs and AT-PC) were significantly enriched at branching points (Fig. 6d).

\section{Discussion}

The aim of this study was to compare and further characterise pericytes isolated from different human tissues by applying $\mathrm{MACS}^{\circledR}$ as a clinically approved isolation method. According to previous work (Corselli et al., 2013; Covas et al., 2008; Crisan et al., 2008) we isolated pericytes based on their expression of CD146 and the absence of CD34. We show that MACS ${ }^{\circledR}$ enrichment can be successfully applied for pericyte enrichment from bone marrow and adipose tissue. Both tissues are routinely used for cell harvesting in clinical practice.

In agreement with earlier studies (Crisan et al., 2012) we found that CD34-CD146+ cells are more abundant in SVF than in BM-MNC populations. This was also reflected in the purity of the obtained cell population (BM: $47 \%$ CD34-CD146+ vs. SVF: $83 \%$ CD34-CD146+). A high percentage of BM CD34-CD146+ cells co-expressed CD45. This CD45+CD34-CD146+ cell population represents lymphocytes, which may express CD146 upon activation (Wang and Yan, 2013). Due to the short life span of lymphocytes and their inability to adhere on tissue culture plastic, these unwanted cells were removed following media exchanges, which was confirmed by the absence of CD45 expressing cells on cultured BM-PC (data not shown).

CD146 is not specific to pericytes (Wang and Yan, 2013). Although endothelial cells were excluded by selecting only CD34-negative cells, it is not guaranteed that all isolated CD146-expressing cells derived from a perivascular localisation in vivo. Another limitation is that perivascular cells themselves present an inhomogeneous cell population. In addition, CD146 expression might be influenced by several environmental factors including hypoxia (Tormin et al., 2011; Wang and Yan, 2013) and thus might be affected by tissue harvest and processing procedures. Therefore, we also characterised MNCs and $\mathrm{SVF}$ in respect to other putative pericyte markers, NG-2 and PDGFR $\beta$. Interestingly, in MNCs the abundance of $\mathrm{CD} 146+\mathrm{NG}-2+\mathrm{PDGFR} \beta+$ cells was in the same range as the CD45-CD34-CD146+ population. In adipose tissue, NG2+PDGFR $\beta+$ cells as well as the population of triple positive cells (CD146+NG2+PDGFR $\beta+$ ) was much smaller compared to the CD45-CD34-CD146+ cell population. However, NG-2 is not uniformly expressed on all pericyte subsets (Crisan et al., 2008). PDGFR $\beta$ might be internalised under certain conditions preventing detection by antibody staining (Nakayama et al., 2013). At this point it remains unclear whether all isolated CD45-CD34-
CD146+ cells represent pericytes in vivo. As discussed above, further research, including in vivo characterisation and developing current isolation procedures to utilise a broader panel more selective markers such as nestin or 3G5 (Mendez-Ferrer et al., 2010; Yuan et al., 2015), will be required to confirm the identity of these cells.

We assessed the potential of pericytes to differentiate along different mesenchymal lineages in order to better understand the function of pericytes in regenerative processes and to evaluate their suitability for tissue engineering applications and cell therapies. Here, we report that the general differentiation potential of pericytes from AT and BM reflects the potential of the respective full stem cell population in vitro. This finding is in line with the assumption that CD45-CD34-CD146+ pericytes represent a cell population with similar characteristics to MSCs (Covas et al., 2008; Crisan et al., 2008). Interestingly, our data show that AT- and BM-PC are more efficient in mineral deposition compared to the respective MSC population, suggesting that enrichment of CD34-CD146+ cells could be a promising strategy for bone tissue engineering. The focus of the current study was to evaluate the plasticity of pericytes, i.e. to investigate their potential to differentiate into different lineages as well as their role in angiogenesis. Due to the limited cell numbers, this prevented a more comprehensive analysis of osteogenic differentiation of cells. Future studies will be required to assess the osteogenic potential of CD34-CD146+ cells in comparison to the full MSC population in more detail, as for example the expression of genes and proteins involved in osteogenic differentiation of cells.

In the current study, chondrogenic differentiation was induced by TGF- $\beta 1$; under this condition AT-derived cells did not show glycosaminoglycan production. It has been described before that chondrogenic differentiation of AT-MSCs is enhanced by supplementation of BMP-6 (Estes et al., 2010; Estes et al., 2006; Hennig et al., 2007; Puetzer et al., 2010). We have performed additional experiments with AT-MSCs from two donors, which were stimulated for an extended 4-week-period and in presence of BMP-6. However, these donors failed to differentiate chondrogenically. More donors have to be tested to confirm the results. Besides, it is known that differences in culture conditions have a significant impact on the differentiation potential of MSCs. In fact, recent publications which showed chondrogenic differentiation capability of ATMSCs, have applied induction periods for up to 6 weeks (Hennig et al., 2007) and supplemented the culture medium with FBS (Estes et al., 2010; Kohli et al., 2015). In serum containing media lot differences might have a significant influence on the efficiency of chondrogenic induction.

Both R-PC and PL-PC failed to differentiate towards an adipogenic or chondrogenic lineage suggesting limited regenerative potential of these cell types. However, other groups have shown a multilineage potential for placenta-derived pericytes (Blocki et al., 2013; Crisan et al., 2008). These differences might be due to extended in vitro culture (R-PC and PL-PC used in passage 6-8) and/ or differences in culture conditions. In the current study, we used different culture conditions for different cell types, namely $\alpha$ MEM for MSCs, PGM for the R-PC and PL-PC, 
and a combination of EGM-2 and DMEM-20 \% FBS for AT- and BM-derived PC, according to previously published methods (e.g. Crisan et al., 2008; Blocki et al., 2013). To exclude a direct effect of medium type upon plasticity we performed an additional experiment culturing R-PC for 2 weeks in the different culture media used in this study and characterised the cells afterwards regarding their multilineage and angiogenic potential (Fig. 7). Results revealed morphological changes but no differences in differentiation capacity of R-PC and therefore excluded unwanted effects of using different culture medium. However, it will be of interest for future studies to explore the influence of different culture conditions more systematically, including other cell types and culturing the cells for the full expansion period in the respective medium.

Interestingly, the direct comparison of MSCs and pericytes from different tissues revealed that the specific microenvironment of the organ of origin may influence cell function. This was evident by the fact that cells from AT showed prominent lipid production following adipogenic induction and BM-derived cells showed the strongest calcium deposition upon osteogenic differentiation, which was also confirmed in other studies (Vishnubalaji et al., 2012). Moreover, tissue specific differences in pericyte function were recently reported for pericytes derived from skeletal muscle and myocardium (Chen et al., 2015).

The angiogenic potential of pericytes was studied in a Matrigel ${ }^{\mathrm{TM}}$ assay. In line with another publication (Blocki et al., 2013), we observed that pericyte single cultures did not form networks on Matrigel ${ }^{\mathrm{TM}}$. However, in co-culture with endothelial cells, pericytes integrated into tube-like structures. The tissue source of pericytes did not influence the cumulative length or the branching of the tube-like structures. This is in contrast to the study from Blocki et al. (2013) suggesting that PL-PC and CD34-CD146+ BMPC stabilised the networks, while co-cultures with MSCs resulted in cell aggregates. From the aforementioned study it becomes evident that culture conditions may critically affect the angiogenic potential of cells since CD146- cells grown in pericyte growth medium did not disintegrate the tubular structures in contrast to MSCs which have been cultured in DMEM medium (Blocki et al., 2013). When comparing the number of pericytes localised at branching points in tube-like networks, we observed a significant enrichment for BM-PC, AT-MSCs and AT-PC. This follows the higher content of pericytes within these cell populations which is in turn reflected by the percentage of CD34CD146+ cells in the SVF and after MACS ${ }^{\circledR}$ enrichment, respectively.

In line with earlier publications, our results indicate that pericytes, isolated as CD45-CD34-CD146+ cells, have similar phenotypic and functional properties as the respective full $\mathrm{AT}$ and $\mathrm{BM}$ stem cell population. In fact, our data shows that AT-PC and BM-PC are more efficient in osteogenic differentiation compared to the respective full stem cell population, which is in line with our previous work showing that the presence of CD34+ cells in bone marrow reduced the osteogenic potential of the corresponding full stem cell population (Duttenhoefer et al., 2015). We report for the first time a MACS ${ }^{\circledR}$ enrichment strategy requiring only minimal manipulation of cells which may be utilised in a clinical setting. It will be interesting to investigate the functionality of the freshly enriched cells in future in vitro and in vivo studies. In particular, cell therapies and tissue engineering strategies applying fresh cells (onestep procedures) might benefit from such an enriched population of multipotent precursors which exhibit the potential to stimulate tissue regeneration and contribute to neovascularisation. For clinical translation such intraoperative procedures would be favourable. Finally, our results suggest that the regenerative potential of pericytes is dependent upon tissue origin. This is of major importance for the application of cells for regenerative therapies and should be further evaluated in future studies.

\section{Acknowledgements}

The authors thank Dr Markus Loibl, Dr Lorin Benneker and Prof Dirk Johannes Schaefer for providing human bone marrow and adipose tissue samples (in agreement with the local ethic committees). The authors thank AOER/ AO Foundation for funding. The FACS BD ArialII was kindly donated by the Innovationsstiftung Graubünden. We confirm that the authors have no conflicts of interest to declare and there has been no significant financial support for this work that could influence its outcome.

\section{References}

Aguilera KY, Brekken RA (2014) Recruitment and retention: factors that affect pericyte migration. Cell MolLife Sci 71: 299-309.

Armulik A, Abramsson A, Betsholtz C (2005) Endothelial/pericyte interactions. Circ Res 97: 512-523.

Blocki A, Wang Y, Koch M, Peh P, Beyer S, Law P, Hui J, Raghunath M (2013) Not all MSCs can act as pericytes: functional in vitro assays to distinguish pericytes from other mesenchymal stem cells in angiogenesis. Stem Cells Dev 22: 2347-2355.

Caplan AI (2009) Why are MSCs therapeutic? New data: new insight. J Pathol 217: 318-324.

Chen CW, Okada M, Proto JD, Gao X, Sekiya N, Beckman SA, Corselli M, Crisan M, Saparov A, Tobita K, Peault B, Huard J (2013) Human pericytes for ischemic heart repair. Stem Cells 31: 305-316.

Chen WC, Baily JE, Corselli M, Diaz ME, Sun B, Xiang G, Gray GA, Huard J, Peault B (2015) Human myocardial pericytes: multipotent mesodermal precursors exhibiting cardiac specificity. Stem Cells 33: 557-573.

Corselli M, Crisan M, Murray IR, West CC, Scholes J, Codrea F, Khan N, Peault B (2013) Identification of perivascular mesenchymal stromal/stem cells by flow cytometry. Cytometry A 83: 714-720.

Covas DT, Panepucci RA, Fontes AM, Silva WA, Jr., Orellana MD, Freitas MC, Neder L, Santos AR, Peres LC, Jamur MC, Zago MA (2008) Multipotent mesenchymal stromal cells obtained from diverse human tissues share functional properties and gene-expression profile with CD146+ perivascular cells and fibroblasts. Exp Hematol 36: $642-654$ 
Crisan M, Yap S, Casteilla L, Chen CW, Corselli M, Park TS, Andriolo G, Sun B, Zheng B, Zhang L, Norotte C, Teng PN, Traas J, Schugar R, Deasy BM, Badylak S, Buhring HJ, Giacobino JP, Lazzari L, Huard J, Peault B (2008) A perivascular origin for mesenchymal stem cells in multiple human organs. Cell Stem Cell 3: 301-313.

Crisan M, Corselli M, Chen WC, Peault B (2012) Perivascular cells for regenerative medicine. J Cell Mol Med 16: 2851-2860.

da Silva ML, Caplan AI, Nardi NB (2008) In search of the in vivo identity of mesenchymal stem cells. Stem Cells 26: 2287-2299.

Diaz-Flores L, Gutierrez R, Madrid JF, Varela H, Valladares F, Acosta E, Martin-Vasallo P, Diaz-Flores L Jr. (2009) Pericytes. Morphofunction, interactions and pathology in a quiescent and activated mesenchymal cell niche. Histol Histopathol 24: 909-969.

Duttenhoefer F, Lara de Freitas R, Meury T, Loibl M, Benneker LM, Richards RG, Alini M, Verrier S (2013) 3D scaffolds co-seeded with human endothelial progenitor and mesenchymal stem cells: evidence of prevascularisation within 7 days. Eur Cell Mater 26: 49-64.

Duttenhoefer F, de Freitas RL, Loibl M, Bittermann G, Richards RG, Alini M, Verrier S (2015) Endothelial Progenitor Cell Fraction Contained in Bone MarrowDerived Mesenchymal Stem Cell Populations Impairs Osteogenic Differentiation. Biomed Res Int. doi: 10.1155/2015/659542.

Estes BT, Wu AW, Guilak F (2006) Potent induction of chondrocytic differentiation of human adipose-derived adult stem cells by bone morphogenetic protein 6 . Arthritis Rheum 54: 1222-1232.

Estes BT, Diekman BO, Gimble JM, Guilak F (2010) Isolation of adipose-derived stem cells and their induction to a chondrogenic phenotype. Nat Protoc 5: 1294-1311.

Fuchs S, Ghanaati S, Orth C, Barbeck M, Kolbe M, Hofmann A, Eblenkamp M, Gomes M, Reis RL, Kirkpatrick CJ (2009) Contribution of outgrowth endothelial cells from human peripheral blood on in vivo vascularization of bone tissue engineered constructs based on starch polycaprolactone scaffolds. Biomaterials 30: 526-534.

Goerke SM, Plaha J, Hager S, Strassburg S, TorioPadron N, Stark GB, Finkenzeller G (2012) Human endothelial progenitor cells induce extracellular signalregulated kinase-dependent differentiation of mesenchymal stem cells into smooth muscle cells upon cocultivation. Tissue Eng Part A 18: 2395-2405.

Hall-Glenn F, De Young RA, Huang BL, van Handel B, Hofmann JJ, Chen TT, Choi A, Ong JR, Benya PD, Mikkola H, Iruela-Arispe ML, Lyons KM (2012) CCN2/ connective tissue growth factor is essential for pericyte adhesion and endothelial basement membrane formation during angiogenesis. PLoS One 7: e30562.

Helmbold P, Wohlrab J, Marsch WC, Nayak RC (2001) Human dermal pericytes express 3G5 ganglioside--a new approach for microvessel histology in the skin. J Cutan Pathol 28: 206-210.

Hennig T, Lorenz H, Thiel A, Goetzke K, Dickhut A, Geiger F, Richter W (2007) Reduced chondrogenic potential of adipose tissue derived stromal cells correlates with an altered TGFbeta receptor and BMP profile and is overcome by BMP-6. J Cell Physiol 211: 682-691.

Herrmann M, Binder A, Menzel U, Zeiter S, Alini M, Verrier S (2014) CD34/CD133 enriched bone marrow progenitor cells promote neovascularization of tissue engineered constructs in vivo. Stem Cell Res 13: 465-477.

James AW, Zara JN, Zhang X, Askarinam A, Goyal R, Chiang M, Yuan W, Chang L, Corselli M, Shen J, Pang S, Stoker D, Wu B, Ting K, Peault B, Soo C (2012) Perivascular stem cells: a prospectively purified mesenchymal stem cell population for bone tissue engineering. Stem Cells Transl Med 1: 510-519.

Kohli N, Wright KT, Sammons RL, Jeys L, Snow M, Johnson WE (2015) An in vitro comparison of the incorporation, growth, and chondrogenic potential of human bone marrow versus adipose tissue mesenchymal stem cells in clinically relevant cell scaffolds used for cartilage repair. Cartilage 6: 252-263.

Loibl M, Binder A, Herrmann M, Duttenhoefer F, Richards RG, Nerlich M, Alini M, Verrier S (2014) Direct cell-cell contact between mesenchymal stem cells and endothelial progenitor cells induces a pericyte-like phenotype in vitro. Biomed Res Int 2014: 395781.

Martin I, Muraglia A, Campanile G, Cancedda R, Quarto R (1997) Fibroblast growth factor-2 supports ex vivo expansion and maintenance of osteogenic precursors from human bone marrow. Endocrinology 138: 4456-4462.

Mendez-Ferrer S, Michurina TV, Ferraro F, Mazloom AR, Macarthur BD, Lira SA, Scadden DT, Ma'ayan A, Enikolopov GN, Frenette PS (2010) Mesenchymal and haematopoietic stem cells form a unique bone marrow niche. Nature 466: 829-834.

Nakayama A, Nakayama M, Turner CJ, Hoing S, Lepore JJ, Adams RH (2013) Ephrin-B2 controls PDGFRbeta internalization and signaling. Genes Dev 27: 2576-2589.

Puetzer JL, Petitte JN, Loboa EG (2010) Comparative review of growth factors for induction of three-dimensional in vitro chondrogenesis in human mesenchymal stem cells isolated from bone marrow and adipose tissue. Tissue Eng Part B Rev 16: 435-444.

Scherberich A, Galli R, Jaquiery C, Farhadi J, Martin I (2007) Three-dimensional perfusion culture of human adipose tissue-derived endothelial and osteoblastic progenitors generates osteogenic constructs with intrinsic vascularization capacity. Stem Cells 25: 1823-1829.

Seebach C, Henrich D, Wilhelm K, Barker JH, Marzi I (2012) Endothelial progenitor cells improve directly and indirectly early vascularization of mesenchymal stem celldriven bone regeneration in a critical bone defect in rats. Cell Transplant 21: 1667-1677.

Shepro D, Morel NM (1993) Pericyte physiology. FASEB J 7: 1031-1038.

Stark K, Eckart A, Haidari S, Tirniceriu A, Lorenz M, von Bruhl ML, Gartner F, Khandoga AG, Legate KR, Pless R, Hepper I, Lauber K, Walzog B, Massberg S (2013) Capillary and arteriolar pericytes attract innate leukocytes exiting through venules and 'instruct' them with patternrecognition and motility programs. Nat Immunol 14: 4151. 
Tormin A, Li O, Brune JC, Walsh S, Schutz B, Ehinger M, Ditzel N, Kassem M, Scheding S (2011) CD146 expression on primary nonhematopoietic bone marrow stem cells is correlated with in situ localization. Blood 117: 5067-5077.

Vishnubalaji R, Al-Nbaheen M, Kadalmani B, Aldahmash A, Ramesh T (2012) Comparative investigation of the differentiation capability of bone-marrow- and adipose-derived mesenchymal stem cells by qualitative and quantitative analysis. Cell Tissue Res 347: 419-427.

Wang Z, Yan X (2013) CD146, a multi-functional molecule beyond adhesion. Cancer Lett 330: 150-162.

Yu H, Vandevord PJ, Gong W, Wu B, Song Z, Matthew HW, Wooley PH, Yang SY (2008) Promotion of osteogenesis in tissue-engineered bone by pre-seeding endothelial progenitor cells-derived endothelial cells. J Orthop Res 26: 1147-1152.

Yuan K, Orcholski ME, Panaroni C, Shuffle EM, Huang NF, Jiang X, Tian W, Vladar EK, Wang L, Nicolls MR, Wu JY, de Jesus Perez VA (2015) Activation of the Wnt/planar cell polarity pathway is required for pericyte recruitment during pulmonary angiogenesis. Am J Pathol 185: 69-84.

Zhang R, Gao Z, Geng W, Yan X, Chen F, Liu Y (2012) Engineering vascularized bone graft with osteogenic and angiogenic lineage differentiated bone marrow mesenchymal stem cells. Artif Organs 36: 1036-1046.

Zhou J, Lin H, Fang T, Li X, Dai W, Uemura T, Dong $\mathrm{J}$ (2010) The repair of large segmental bone defects in the rabbit with vascularized tissue engineered bone. Biomaterials 31: 1171-1179.

\section{Discussion with Reviewers}

Reviewer I: Bearing in mind issues of scale and translation, in addition to the science, which cell population or sub- population would you recommend to regenerate i) bone and ii) cartilage?

Authors: For the regeneration of a large bone defect, a large number of cells with good osteogenic capabilities would be required. Considering the use of monolayer expanded cells, both adipose and bone marrow-derived cells would be suitable. With regards to the cell harvest from the patient, liposuction might be considered less invasive compared to bone marrow aspiration and therefore favourable. When considering intra-operative cell therapies, for example delivering of CD34-CD146+ cells selected by the CliniMACS ${ }^{\circledR}$ system, suitable cell numbers would most likely only be obtained from adipose tissue. For cartilage tissue regeneration our data suggest limited chondrogenic differentiation capabilities of adipose tissuederived cells which would suggest bone marrow cells as the cell source of choice for cartilage repair. However, before making final conclusion the function of cells has to be confirmed in appropriate in vivo models.

Reviewer II: What is the value of including the R-PC and PL-PC studies? It is not clear if this represents a particularly useful aspect.

Authors: We included these cell types in our study for several reasons. First, both cell types are pooled primary cells which are commercially available, which (i) reduces bias of the results by donor variances and (ii) facilitates the comparability of results to other studies. Secondly, both cells represent "mature" pericytes. Particularly to study the role of cells in angiogenesis we considered these cells as valuable controls to the different MSC and CD34-CD146+ cell populations used in the manuscript.

Editor's Note: Scientific Editor in charge of the paper: Chris Evans. 